\title{
COMPORTAMENTO ESPECTRAL DE SOLOS DE ORIGEM CARBONÁTICA DO MUNICÍPIO DE JUAZEIRO-BA
}

\author{
$\underline{\text { Bruna Suellen Oliveira Mota }^{1} \text {; Deorgia Tayane Mendes de Souza }}{ }^{2}$ e Washington \\ De Jesus Sant'anna Franca Rocha ${ }^{3}$ \\ 1. Bolsista PIBIC/CNPq, Graduanda em Licenciatura em Geografia, Universidade Estadual de Feira de Santana, e- \\ mail: brunasuellen.om@gmail.com \\ 2. Co-Orientadora, Departamento de Ciências Exatas, Universidade Estadual de Feira de Santana, e-mail: \\ deorgiasouza.geo@gmail.com \\ 3. Orientador, Departamento de Ciências Exatas, Universidade Estadual de Feira de Santana, e-mail: \\ francarocha@gmail.com
}

PALAVRAS-CHAVE: Solo, espectrorradiometria de refletância e biblioteca espectral.

\section{INTRODUÇÃO}

Apesar dos condicionantes climáticos, o município de Juazeiro- Ba é caracterizado pela forte agricultura irrigada (suprida pelo rio São Francisco) de frutas tropicais para exportação (DIAS, 2013), tendo como fator de influencia positiva, a litologia carbonática que em conjunto com os demais fatores de formação pedogenética contribuem para a atividade agrícola. $O$ contexto geológico da área de estudo compõe a Formação Caatinga e o Grupo Bambuí, que apesar gêneses distintas, apresentam unidades carbonáticas como litologia principal.

Lepsch (2007) discute a gênese do solo como contínuo e complexo, uma vez que envolve processos com diferentes intensidades e tempos, já que existem diferentes condicionantes que influenciam, tais como o material de origem, atributos climáticos, relevo e atuação biológica.

A atribuição da Espectrorradiometria de Reflectância para estudos pedológicos é relativamente recente, datados em sua maioria a partir da década de sessenta, e vem demonstrando grande potencial conforme afirma Meneses (2001), subsidiando a identificação atributos do solo como, mineralogia, matéria orgânica, propriedades estruturais e texturais (MOREIRA, 2005).

\section{MATERIAL E MÉTODOS OU METODOLOGIA (ou equivalente)}

O grupo Bambuí e a Formação Caatinga constituem o material base, rochas carbonáticas que deram origem ao processo pedogenético no município de Juazeiro-BA, em conjunto com os demais fatores de formação, e que sustentam atividade agrícola desse município. Juazeiro, localizado no extremo norte do estado da Bahia, é um dos maiores do estado, possui população de 197.965 habitantes, segundo o censo realizado em 2010 pelo Instituto Brasileiro de Geografia e Estatística (IBBE) estando inserido na região de clima semiárido, cujo tipo climático predominante é o Aw' - Tropical com chuvas de verão-outono (KOPPEN-GEIGER, 1928).

Inicialmente foram realizadas pesquisas bibliográficas focalizando nas seguintes temáticas: Solo, Espectrorradiometria em solo e formações geológicos com ênfase em rochas carbonáticas. Em seguida foi realizada a coleta de dados que serviram de base para a caracterização da área de estudo bem como a classificação de solos de origem carbonática. A partir da realização desse estudo realizou-se o trabalho de campo que teve uma duração de 3 dias, e objetivou a coleta de amostras de solos de origem carbonática do município de Juazeiro, as quais foram posteriormente secas, pesadas, destorroadas e peneiradas. O próximo procedimento realizou-se no Laboratório de 
Espectrorradiometria - LABESPECTRO, do Programa de Pós-Graduação em Ciências da Terra e do Ambiente da UEFS, que dispõe de dois Espectrorradiômetros ASD FieldSpec, que abrangem o intervalo de 350 a 2500 nanômetros. Tais procedimentos visaram a identificação das medidas espectrorradiométricas, através das assinaturas espectrais.

Feita as análises das assinaturas espectrais e consequentemente a identificação dos minerais presentes na amostra de solo, foi realizada a produção da biblioteca espectral, e verificou-se a ocorrência de padrões espectrais de solos, sendo posteriormente comparada com os dados da Serviço Geológico dos Estados Unidos (USGS).

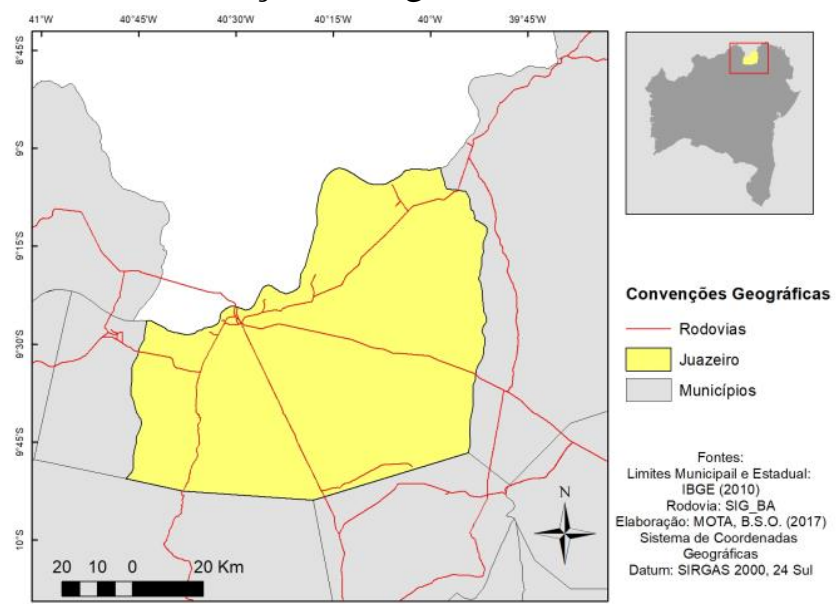

Figura 01- Mapa de localização de Juazeiro- Ba

\section{RESULTADOS E/OU DISCUSSÃO (ou Análise e discussão dos resultados)}

Foram coletados perfis de solos de origem carbonática com base no estudo realizado no pré-campo. Estes foram denominados 69, 74 e 79, sendo classificados respectivamente em: Neossolo Litólico, Vertissolo Ebânico, e Chernossolo Ebânico Carbonático Vertissolico.
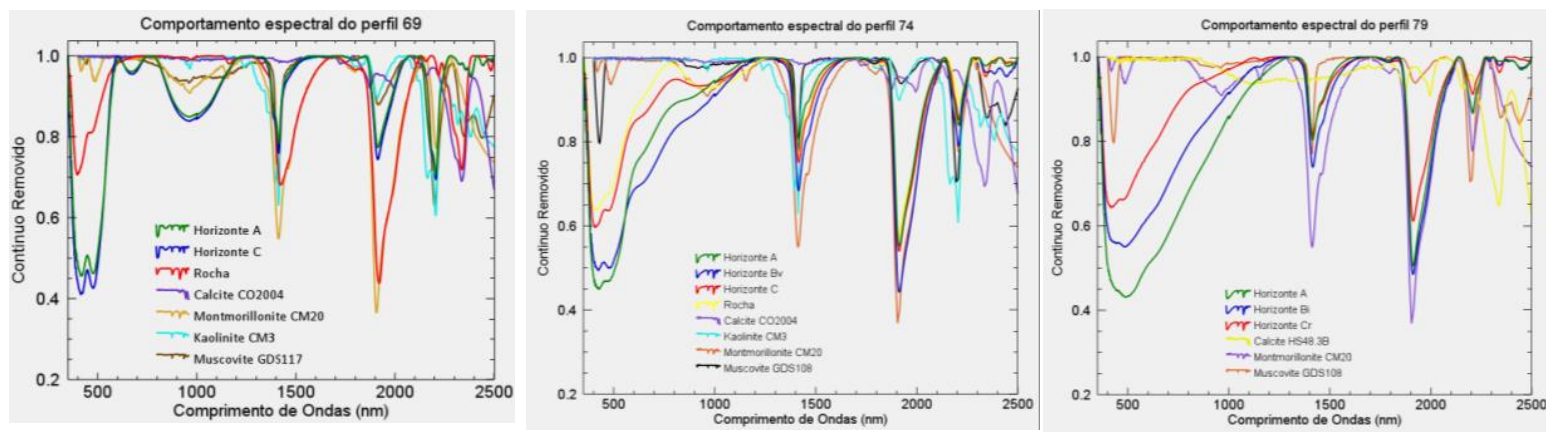

Figura 02- Assinaturas espectrais dos perfis 69, 74 e 79

O Perfil 69 foi coletado no Junco, foi classificado como Neossolo litólico, com espessura de $75 \mathrm{~cm}$, definido em 2 horizontes A e C com o contato lítico com o calcário o que foi perceptível afloramento em superfície. O perfil estava localizado sobre uma área plana, declividade $0-5^{\circ}$.

Foi possível verificar a presença de Calcita, Caulinita, Goethita, Muscovita e Montmorilonita. Infere-se em ambos os horizontes a Muscovita a partir dos picos de absorção característicos em 1412nm e 2207nm e enquanto a Montmorilonita em Montmorilonita em 2207nm também e em 1900nm pela absorção da molécula de água. Já com as feições de absorção da Caulinita nas bandas 1412nm 2205nm, 2354nm e 
$2384 \mathrm{~nm}$, infere-se que o mineral é incipiente devido tanto pela assinatura espectral que apresenta, a partir da modelagem da feição diagnóstica em formação, quanto pela profundidade das feições $2354 \mathrm{~nm}$ e $2384 \mathrm{~nm}$, que indicam pouca quantidade do mineral. Segundo Teixeira (2001) presença de tal mineral se dá com a ocorrência da hidrólise parcial do tipo monossialitização, sendo este um argilomineral de relação Si:Al 1:1, ou seja, não expansivo. Portanto o processo de intemperização vem transformando a Montmorilonta em Caulinita a partir da liberação da Sílica

As feições $1412 \mathrm{~nm} 2205 \mathrm{~nm}$ apresentam profundidades marcantes tanto no horizonte A quanto no horizonte C, entretanto em $2354 \mathrm{~nm}$ e $2384 \mathrm{~nm}$ os valores são baixos. Enquanto a Goethita em 660nm, 770nm e $912 \mathrm{~nm}$, podendo ser comprovado pelo fato de o mineral atribuir a cor amarelada ao solo.

Já a assinatura espectral da rocha apresentou picos de absorção em 2154nm e 2330nm característico da Calcita, com profundidades consideráveis. Tal mineral não foi identificado no solo, permitindo constatar que a causa é em razão da lixiviação, que promove a liberação desse rápida do material.

O perfil 74 coletado está localizado no distrito de Juazeiro, Carnaíba do Sertão. Em condições de elevo plano com pouca declividade $\left(0-5^{\circ}\right)$, foi classificado como Vertissolo Ebânico. Apresentando profundidade de $70 \mathrm{~cm}$, os horizontes foram definidos em três, A, B vértico e $\mathrm{C}$ respectivamente. Observou-se o afloramento em superfície de rocha calcárea, assim como o perfil 69.

Conforme as assinaturas espectrais foi possível inferir nos horizontes A e B a presença de Montmorilonita, Muscovita, Caulinita, e Calcita. Entretanto, as feições do horizonte B exibem maior profundidade em todos os picos, por se tratar de um horizonte vértico, verifica-se uma maior quantidade de argilas expansivas 2:1 como a Montmorilonita (presença de fendas ou slinksides), notando-se as feições em 1412 devido a absorção da molécula de água e 2206, ambas as bandas com notável profundidade. Vertissolos são pouco permeáveis, o que restringe a sua drenagem (LEPSCH, 2007) caracterizando baixo grau de intemperismo químico.

O mineral associado as feições de absorção constatadas na rocha em 2216nm e 2342nm foi a Calcita que apresentou valores mínimos de profundidade, constatando uma pouca qualidade do mineral supracitado. Pode-se inferir que isso deve-se ao fato de a Calcita ser um mineral pouco estável como discute Teixeira (2001) facilitando a atuação do intemperismo.

Já o perfil 79 foi coletado na Carnaíba, Chernossolo Ebânico Carbonático Vertissolico, foi aberto até $80 \mathrm{~cm}$ de profundidade. Identificou-se três horizontes sendo eles, A, B insipiente, $\mathrm{Cr}$.

O horizonte A, apresenta absorções associadas a presença de Calcita, Muscovita e Montmorilonita. O mesmo ocorre para o horizonte $\mathrm{B}$, e este apresenta a maior profundidade na resposta referente a absorção de H2O, em 1413nm.

Já o horizonte $\mathrm{C}$, apresenta as absorções menos profundas em todas as feições. Todavia possui absorções em $484 \mathrm{~nm}$ e $425 \mathrm{~nm}$ inferindo a Goethita e em $2342 \mathrm{~nm}$ a Calcita, entretanto as profundidades para os três perfis indicam pouca quantidade desse mineral, inferindo que esta sendo lixiviado.

A partir das observações realizadas, verificou-se a existência de padrões espectrais característicos dos solos de origem carbonática, considerando que ambos os perfis 
foram padronizadas com Comprimento de Ondas de 350nm à 2500nm. Quanto a composição mineralógica, em geral detectou-se a existência de Calcita, Caulinita, Goethita, Ilita, Montmorilonita e Muscovita. Suas bandas de absorções representativas visualizam-se na Figura 02 a qual observa-se a existência de um padrão principalmente na faixa do Infravermelho Médio e Infravermelho de Ondas Curtas, um vez que todos os perfis apresentam assinaturas marcadas pelas feições principais em 1412nm, 1910nm e $2207 \mathrm{~nm}$.

\section{CONSIDERAÇÕES FINAIS}

A partir dos de solos obtidos foi possível a identificação das classes Neossolo, Vertissolo e Chernossolo, ambos tendo como material de origem as rochas carbonáticas. Dentre eles foram inferidos por meio das técnicas aplicadas, os minerais: Caulinita, Calcita, Ilita, Montmorilonita e Muscovita. As absorções predominantes identificadas foram na faixa do Infravermelho de Ondas Curtas, sendo estas resultado de movimentos vibracionais moleculares como discute Meneses (2001).

Em locais onde há baixa pluviosidade, como na área de estudo em questão, há a ocorrência de evapotranspiração e movimentos de água ascendente, que condicionam a precipitação da calcita.

As rochas carbonáticas são menos resistentes a atuação do intemperismo, afirma Teixeira (2001). O mesmo ocorre com a calcita, o que pode ser observado pela ausência da mesma em alguns perfis, como o 69.

Os processos intempéricos químicos se fazem predominantes nos perfis analisados, considerando que apesar de se tratar de um ambiente semiárido, possui relevo que favorece a infiltração e drenagem da água, justificando a existência dos minerais encontrados.

\section{REFERÊNCIAS}

DIAS, R. S. et al. Alteração da produção agrícola e uso da terra do município de juazeiro (Bahia) de 1990 a 2008: aplicação da metodologia do shift-share. In: XVI Simpósio Brasileiro de Sensoriamento Remoto - SBSR, 2013, Foz do Iguaçu, PR, Anais Brasil, 13 a 18 de abril de 2013, INPE.

LEPSCH, I. F. 19 lições de pedologia. Oficina de Textos, 2007.

Köppen, W.; Geiger, R. Klimate der Erde. Gotha: Verlag Justus Perthes. 1928. Wallmap $150 \mathrm{~cm} \times 200 \mathrm{~cm}$.

MENESES, Paulo R.; MADEIRA NETTO, J. da S. Sensoriamento remoto: reflectância dos alvos naturais. Editora Universidade de Brasilia; Planaltina: Embrapa Cerrados, 2001.

MOREIRA, Maurício Alves. Fundamentos do sensoriamento remeto e metodologias de aplicação. 3 ed. Atual. ampl Viçosa: Ed.UFV 2005. 320p.

TEIXEIRA, W. et al. Decifrando a terra. Oficina Textos, 2001. 